\title{
PERBANDINGAN KARAKTERISTIK THIN SURFACING HOT MIX ASPHALT DI LABORATORIUM DENGAN HASIL LAPANGAN SERTA ANALISIS SKID RESISTANCE.
}

\author{
Yusuf Suryoaji ${ }^{1}$, Ary Setyawan'2), Agus Sumarsono ${ }^{3)}$ \\ 1)Mahasiswa Program S1 Teknik Sipil, Universitas Sebelas Maret \\ 2) 3) Pengajar Program Studi Teknik Sipil , Universitas Sebelas Maret \\ Jalan Ir Sutami 36A, Surakarta 57126 E-mail : ysuryoaji@gmail.com
}

\begin{abstract}
The purpose of this research is to compare samples of Thin Surfacing made in the laboratory by sampling the results of the coring from the field using Marshall test, Indirect Tensile Strength test, and how much influence the amount of compaction on the skid resistance.

The method used in this study is experimental conducted at the Sebelas Maret University Highway Surakarta Laboratory and in the village of Madegondo, Grogol district, Sukoharjo district. For coring samples, taken from the road made in the village Madegondo with dimensions of $3 \mathrm{~m} \times 1 \mathrm{~m}$ and every 1 meter done variation of rolling. The rolling variation is done 10 times, 15 times, and 20 times rolling. Before the coring process is done skid resistance testing with rolling straightedge tool. After that, it is done coring on each compaction variation to take samples for Marshall and Indirect Tensile Strength testing.

The result of the test object analysis showed that the value of stability, flow and the value of ITS samples from the coring result is far from the sample made in the laboratory although some variations of compaction have been done. While the amount of skid resistance value of several variations of gilasan as many as 10 trajectories, 15 trajectories and 20 consecutive trajectory decreased. This shows that the smaller the PrI coefficient the better the level of bitumen flatness. Conversely, the greater the PrI coefficient value indicates rough road surface texture and increases road surface roughness

Key Words : Indirect Tensile Strength, Skid Resistance
\end{abstract}

\begin{abstract}
Abstrak
Tujuan dari penelitian ini adalah membandingkan sampel Thin Surfacing yang dibuat di laboratorium dengan sampel hasil coring dari lapangan menggunakan pengujian Marshall, Indirect Tensile Strength test, dan seberapa besar pengaruh jumlah pemadatan terhadap skid resistance.

Metode yang digunakan pada penelitian ini adalah eksperimental yang dilaksanakan di Laboratorium Jalan Raya Universitas Sebelas Maret Surakarta dan di desa Madegondo, kecamatan Grogol, kabupaten Sukoharjo. Untuk sampel hasil coring, diambil dari jalan yang di buat buat di desa Madegondo dengan dimensi $3 \mathrm{~m}$ x $1 \mathrm{~m}$ dan setiap 1 meter dilakukan variasi pemadatan. Adapun variasi pemadatan yang dilakukan yaitu 10 gilasan, 15 gilasan, dan 20 gilasan. Sebelum dilakukan proses coring dilakukan pengujian skid resistance dengan alat rolling straightedge. Setelah itu dilakukan, maka dilakukan coring pada setiap variasi pemadatan guna mengambil sampel untuk pengujian Marshall dan Indirect Tensile Strength.

Hasil analisis benda uji menunjukkan bahwa besar nilai stabilitas, flow dan nilai ITS sampel hasil coring jauh dari sampel yang dibuat di laboratorium meskipun telah dilakukan beberapa variasi pemadatan. Sedangkan besarnya nilai skid resistance dari beberapa variasi gilasan sebanyak 10 lintasan, 15 lintasan dan 20 lintasan berturut-turut menurun. Hal ini menunjukkan bahwa semakin kecil nilai koefisien PrI semakin baik tingkat kerataan aspal. Sebaliknya, semakin besar nilai koefisien PrI mengindikasikan tekstur permukaan jalan yang kasar dan meningkatkan kekesatan permukaan jalan.
\end{abstract}

(Kata kunci : Indirect Tensile Strength, Skid Resistance) 


\section{PENDAHULUAN}

Banyak penelitian terdahulu yang meneliti tentang karakteristik dari Thin Surfacing serta membandingkannya. Adapun karakteristik yang di teliti dan dibandingan antara lain nilai stabilitas, flow, nilai Indirect Tensile Strength, dan nilai Unconfined Compressive Strength.

Pada penelitian Iskandar (2016), dilakukan perbandingan karakteristik Thin Surfacing nilai stabilitas dan nilai flow antara sampel dengan aspal pen 60/70 dan sampel dengan aspal modifikasi merk starbit E-55. Pada penelitian tersebut didapat nilai stabilitas dan nilai flow yang tinggi pada sampel dengan aspal modifikasi merk starbit E-55.

Sehingga dalam penelitian ini akan dilakukan perbandingan karakteristik Tbin Surfacing antara sampel laboratorium dengan sampel hasil coring dari lapangan dengan aspal modifikasi merk starbit E-55. Adapun karakteristik yang dibandingakan dalam penelitian ini antara lain adalah nilai stabilitas, nilai flow, dan nilai Indirect Tensile Strength. Selain itu dilakukan pula pengujian skid resistance dengan menggunakan alat rolling straightedge pada sampel di lapangan guna mengetahui nilai Profil Ride Index.

\section{LANDASAN TEORI}

Spesifikasi Thin Surfacing Hot Mix Asphalt mengacu pada National Asphalt Pavement Association (NAPA). Gradasi yang digunakan pada campuran ini adalah gradasi envelop yang merupakan standar dari North Carolina. Maksimum ukuran agregat penyusun Thin Surfacing Hot Mix Asphalt ini adalah $12,5 \mathrm{~mm}$ atau tertahan oleh saringan nomor $1 / 2$

Keunggulan dari Thin Surfacing Hot Mix Asphalt yaitu umur layan yang panjang, permukaan yang halus, mampu menahan lalu lintas yang berat dan tegangan geser yang besar, skid resistance yang tinggi, dan mudah perawatannya (Newcomb, 2009)..

Berdasarkan British Broad Agreement HAPAS, tebal dari Thin Surfacing Hot Mix Asphalt dibagi menjadi 3 tipe, yaitu:

- Tipe A dengan ketebalan kurang dari $18 \mathrm{~mm}$

- Tipe B dengan ketebalan antara $18-25 \mathrm{~mm}$

- Tipe $\mathrm{C}$ dengan ketebalan antara $25-40 \mathrm{~mm}$

Dalam penelitian ini kami menggunakan tipe $C$ dengan ketebalan antara $25-40 \mathrm{~mm}$ untuk diterapkan dilapangan karena ketebalan tipe $\mathrm{C}$ diperuntukkan lalu lintas berat dan penelitian yang dilakukan sebelumnya juga menggunakan tipe $\mathrm{C}$

\section{TAHAPAN PENELITIAN}

Dalam penelitian ini dilakukan beberapa tahap penelitian yakni :

1. Persiapan alat dan bahan

Pada tahap ini peneliti mempersiapkan alat dan bahan sebelum memulai penelitian. Melakukan uji bahan dengan shieve analysis untuk menyamakan gradasi campuran pada sampel yang akan dibuat dengan standar gradasi North Carolina untuk kelayakan sampel thin surfacing.

2. Pembuatan sampel

Pada tahap ini peneliti membuat sampel di laboratorium untuk mencari kadar aspal optimum. Dilakukan 75 kali pemadatan untuk sampel yang dibuat di laboratorium. Dari kadar aspal optimum yang didapat digunakan untuk penghamparan aspal di lapangan. Dilakukan beberapa variasi gilasan untuk aspal yang telah dihampar dilapangan yakni 10, 15 dan 20 gilasan. Kemudian dari beberapa variasi gilasan tersebut dilakukan coring guna mendapatkan sampel untuk diteliti nantinya.

3. Pengujian sampel

Dari sampel yang dibuat di laboratorium dan sampel hasil coring dari lapangan dilakukan beberapa pengujian yakni pengujian Marshall dan pengujian Indirect Tensile Strength. Pada aspal yang telah dihamparkan dilapangan dilakukan uji Skid Resistance sebelum dilakukan coring. 
4. Analisis data dan pembahasan

Pada tahap ini peneliti akan melakukan analisis dan pembahasan pada data yang didapat dari hasil pengujian yang telah dilakukan.

5. Kesimpulan

Pada tahap ini peneliti melakukan penarikan kesimpulan dari analisis data yang berhubungan dengan tujuan dari penelitian.

\section{HASIL DAN PEMBAHASAN}

Bahan dasar yang diuji dalam penelitian ini adalah agregat, aspal polimer starbit E-55. Pemeriksaan bahan dilakukan di Laboratorium Jalan Raya Fakultas Teknik Universitas Sebelas Maret Surakarta. Hasil Pemeriksaan agregar dan aspal disajikan dalam Tabel 1, Tabel 2, dan Tabel 3.

Tabel 1. Hasil Pemeriksaan Agregat Kasar

\begin{tabular}{lc}
\hline Berat sampel kering oven & $6567.5 \mathrm{mg}$ \\
\hline Berat sampel jenuh kering permukaan (SSD) & $6710 \mathrm{mg}$ \\
\hline Berat sampel di dalam air & $4160.5 \mathrm{mg}$ \\
\hline Berat jenis bulk & $2.576 \mathrm{gr} / \mathrm{cc}$ \\
\hline Berat jenis SSD & $2.632 \mathrm{gr} / \mathrm{cc}$ \\
\hline Berat jenis semu (apparent) & $2.729 \mathrm{gr} / \mathrm{cc}$ \\
\hline Penyerapan air & $2.170 \%$ \\
\hline
\end{tabular}

Tabel 2. Hasil Pemeriksaan Agregat Halus

\begin{tabular}{lc}
\hline Berat sampel kering oven & $6567.5 \mathrm{mg}$ \\
\hline Berat sampel jenuh kering permukaan (SSD) & $6710 \mathrm{mg}$ \\
\hline Berat sampel di dalam air & $4160.5 \mathrm{mg}$ \\
\hline Berat jenis bulk & $2.576 \mathrm{gr} / \mathrm{cc}$ \\
\hline Berat jenis SSD & $2.632 \mathrm{gr} / \mathrm{cc}$ \\
\hline Berat jenis semu (apparent) & $2.729 \mathrm{gr} / \mathrm{cc}$ \\
\hline Penyerapan air & $2.170 \%$ \\
\hline
\end{tabular}

Tabel 3. Hasil Pemeriksaan Aspal

\begin{tabular}{lc}
\hline Berat Jenis & $1.053 \mathrm{~g} / \mathrm{cc}$ \\
\hline Penetrasi & $60.1 \mathrm{~mm}$ \\
\hline Titik lembek & $54.8^{\circ} \mathrm{C}$ \\
\hline Titik nyala & $320^{\circ} \mathrm{C}$ \\
\hline Titik bakar & $348^{\circ} \mathrm{C}$ \\
\hline Daktilitas & $128.5 \mathrm{~cm}$ \\
\hline Kelekatan terhadap agregat & $98 \%$ \\
\hline
\end{tabular}

Setelah agregat selesai diperiksa maka dilakukan pemeriksaan untuk gradasi dari agregat yang akan dipakai. Pada penelitian ini menggunakan beberapa ukuran agregat yang diambil dari PT.Pancadharma yakni ukuran 1", ukuran 1/2" dan abu batu. Berikut hasil pemeriksaan gradasi disajikan dalam Tabel 4. 
Tabel 4. Hasil Pemeriksaan Gradasi

\begin{tabular}{cccc}
\hline & ukuran 1" & ukuran 1/2" & abu batu \\
\hline $\begin{array}{c}\text { No } \\
\text { Saringan }\end{array}$ & $\begin{array}{c}\text { Komulatif } \\
\text { Lolos }(\%)\end{array}$ & $\begin{array}{c}\text { Komulatif } \\
\text { Lolos }(\%)\end{array}$ & $\begin{array}{c}\text { Komulatif } \\
\text { Lolos }(\%)\end{array}$ \\
\hline $3 / 4^{\prime \prime}$ & 100 & 100 & 100 \\
\hline $1 / 2^{\prime \prime}$ & 72.69 & 99.22 & 100 \\
\hline $3 / 8^{\prime \prime}$ & 22.6 & 93.22 & 100 \\
\hline 4 & 1.61 & 37.37 & 97.3 \\
\hline 8 & 1.49 & 5.49 & 90.53 \\
\hline 50 & 1.37 & 1.92 & 37.67 \\
\hline 200 & 0.6 & 0.52 & 13.06 \\
\hline PAN & 0 & 0 & 0 \\
\hline
\end{tabular}

\section{Penentuan Kadar Aspal Optimum}

Penentuan kadar aspal optimum dilakukan dengan pengujian Marshall. Dalam pengujian Marshall dilakukan perkiraan kadar aspal sementara dengan beberapa variasi yaitu 4,5\%, 5\%, 5,5\%,6\%, dan 6,5\%. Data hasil Marshall test disajikan dalam tabel 5.

Tabel 5. Hasil Pengujian Marshall sampel di lab.

\begin{tabular}{cccc}
\hline$\%$ aspal & stabilitas $(\mathrm{kg})$ & flow $(\mathrm{mm})$ & Marshall Quotient $(\mathrm{kg} / \mathrm{mm})$ \\
\hline 4.5 & 1586.88 & 2.78 & 573.078 \\
\hline 5 & 1691.232 & 2.53 & 670.645 \\
\hline 5.5 & 1834.981 & 2.38 & 2.38 \\
\hline 6 & 1380.959 & 2.37 & 589.276 \\
\hline 6.5 & 1103.493 & 2.63 & 421.013 \\
\hline
\end{tabular}

Dari data tersebut didapat persamaan regresi $\mathrm{y}=-469.49 \mathrm{x} 2+4967 \mathrm{x}-12143$, sehingga akan ditemukan nilai y maksimal jika $\mathrm{x}=5,296 \approx 5,3 \%$. Jadikadar aspal optimum yang digunakan sebesar $5.3 \%$ Setelah mendapat kadar aspal optimum kemudian dibuat benda uji untuk pengujian Marshall dan ITS. Berikut adalah hasil Marshall Properties dengan kadar aspal optimum yang disajikan dalam Tabel 6.

Tabel 6. Marshall Properties dengan kadar aspal optimum

\begin{tabular}{lc}
\hline Hasil Marshall & $\begin{array}{c}\text { Nilai Campuran Thin } \\
\text { Surfacing }\end{array}$ \\
\hline Stabilitas $(\mathrm{Kg})$ & 1749.62 \\
\hline Flow $(\mathrm{mm})$ & 2.55 \\
\hline MQ $(\mathrm{Kg} / \mathrm{mm})$ & 683.7642107 \\
\hline
\end{tabular}

\section{Hasil Marshall Test Hasil Coring}

Dari data yang di dapat sebelumnya, kita mengetahui bahwa kadar aspal optimum sebesar 5,3 $\%$. Dari kadar aspal optimum tersebut kemudian diaplikasikan di lapangan. Pada penelitian 
ini dilakukan sekali pemadatan dengan variasi lintasan yaitu 10 lintasan, 15 lintasan, dan 20 lintasan. Kemudian dilakukan coring pada setiap variasi lintasan tersebut untuk dilakukan beberapa pengujian pada sampel. Untuk hasil uji Marshall dapat dilihat pada Tabel 7.

Tabel 7. Data Marshall Test Hasil Coring di Lapangan

\begin{tabular}{ccccc}
\hline no. sampel & $\%$ aspal & stabilitas $(\mathrm{kg})$ & $\begin{array}{c}\text { flow } \\
(\mathrm{mm})\end{array}$ & $\begin{array}{c}\text { Marshall Quotient } \\
(\mathrm{kg} / \mathrm{mm})\end{array}$ \\
\hline 10 & 5.3 & 490.05 & 3.43 & 145.19 \\
\hline 15 & 5.3 & 648.52 & 3.07 & 209.15 \\
\hline 20 & 5.3 & 733.17 & 3.03 & 242.10 \\
\hline
\end{tabular}

\section{Hasil Uji Kuat Tarik Tidak Langsung}

Hasil dari pengujian benda uji dengan menggunakkan alat Uji Kuat Tarik Tidak Langsung didapat kuat tarik dengan satuan $\mathrm{lb}$, kemudian dilakukan penghitungan nilai kuat tarik dengan satuan $\mathrm{KPa}$ dan kemudian dilakukan konversi satuan dari $\mathrm{kg} / \mathrm{m} 2 \mathrm{ke} \mathrm{KPa}$. Untuk hasil perhitungan ITS sampel laboratorium disajikan dalam Tabel 8 dan untuk perhitungan ITS sampel coring disajikan dalam Tabel 9.

Tabel 8. Perhitungan ITS sampel laboratorium

\begin{tabular}{cccc}
\hline \multirow{2}{*}{$\begin{array}{c}\text { kode } \\
\text { sampel }\end{array}$} & $\begin{array}{c}\text { Kuat Tarik } \\
\text { Terkalibrasi }(\mathrm{Pi})\end{array}$ & \multicolumn{2}{c}{ ITS } \\
\cline { 2 - 4 } & $(\mathrm{kg})$ & $(\mathrm{kg} / \mathrm{m} 2)$ & $(\mathrm{kpa})$ \\
\hline 1 & 311.53248 & 71347.84 & 699.71 \\
\hline 2 & 329.85792 & 79004.83 & 774.80 \\
\hline 3 & 348.18336 & 81223.89 & 796.56 \\
\hline rata - rata & $\mathbf{3 2 9 . 8 5 7 9 2}$ & $\mathbf{7 7 1 9 2 . 1 9}$ & $\mathbf{7 5 7 . 0 2}$ \\
\hline
\end{tabular}

Tabel 9. Perhitungan ITS sampel hasil coring di lapangan

\begin{tabular}{cccc}
\hline \multirow{2}{*}{$\begin{array}{c}\text { kode } \\
\text { sampel }\end{array}$} & $\begin{array}{c}\text { Kuat Tarik Terkalibrasi } \\
(\mathrm{Pi})\end{array}$ & \multicolumn{2}{c}{ ITS } \\
\cline { 2 - 4 } & $(\mathrm{kg})$ & $(\mathrm{kg} / \mathrm{m} 2)$ & $(\mathrm{kpa})$ \\
\hline 10 & 128.27808 & 20995.40 & 205.90 \\
\hline 15 & 177.14592 & 28713.82 & 281.60 \\
\hline 20 & 232.12224 & 36813.13 & 361.03 \\
\hline
\end{tabular}

Dalam penelitian ini didapatkan beberapa nilai yakni Marshall Quotient dan ITS dari sampel lab dan sampel hasil coring dilapangan. Marshall Quotient adalah nilai yang menunjukkan perbandingan antara nilai stabilitas dengan nilai flow yang dinyatakan dalam $\mathrm{kg} / \mathrm{mm}$. Sehingga akan dibandingkan nilai stabilitas dan nilai flow dari sampel lab dan sampel hasil coring di lapangan. Dari pengujian ITS didapatkan nilai kuat tarik tidak langsung dari sampel yang telah dibuat. Adanya variasi gilasan menunjukkan semakin besar gilasan yang dilakukan maka akan semakin baik pula nilai yang didapat. Dari ketiga variasi gilasan tersebut hasilnya jauh dengan hasil sampel yang di buat di laboratorium.

\section{Hasil Uji Skid Resistance}

Dalam pengujian ini didapat nilai Profil Ride Index (PRI) yang menunjukkan perbedaan tekstur pada jalan yang telah dilakukan pengujian. Perubahan-perubahan tekstur permukaan jalan pada setiap gilasan lintasan dijelaskan sebagai berikut dalam gambar 1. 


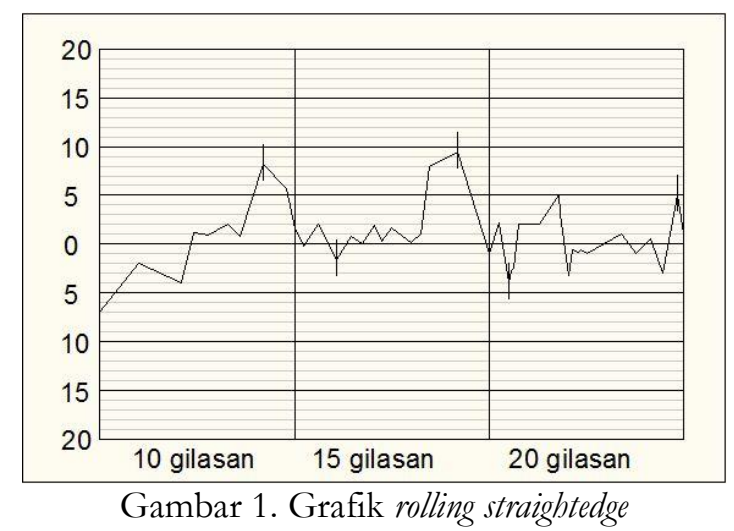

Setelah dilakukan pengujian, didapat grafik setiap gilasan seperti pada gambar 1. Selanjutnya perhitungan nilai PrI setiap gilasan disajikan pada tabel 10.

Tabel 10. Profil Ride Index (PrI) Grafik Thin Surfacing

\begin{tabular}{cccc}
\hline Grafik & PrI Point $(\mathrm{mm})$ & Jarak $(\mathrm{m})$ & $\begin{array}{c}\text { PrI Zero Null Band } \\
(\mathrm{mm} / \mathrm{m})\end{array}$ \\
\hline 10 gilasan & $8+7$ & 1 & 7,5 \\
\hline 15 gilasasn & $9,5+1,5$ & 1 & 5,5 \\
\hline 20 gilasan & $5+4$ & 1 & 4,5 \\
\hline
\end{tabular}

Dari tabel 10, menunjukkan perbandingan nilai Profil Ride Index (PrI) mengalami penurunan dari 10 kali pemadatan, 15 kali pemadatan, 20 kali pemadatan. Grafik untuk segmen 20 kali pemadatan menunjukkan nilai Profil Ride Index yang kecil. Hal ini berarti tekstur permukaan yang dimiliki segmen 20 kali pemadatan lebih halus dibandingkan dengan segmen lainnya. Sedangkan grafik untuk segmen 10 kali pemadatan menunjukkan nilai Profil Ride Index yang lebih besar daripada segmen lainnya. Hal ini berarti tekstur permukaan yang dimiliki segmen 10 kali pemadatan lebih kasar daripada segmen lainnya.

\section{KESIMPULAN}

Setelah dilakukan penelitian tentang perbandingan karakteristik thin surfacing dan juga perhitungan skid resistance didapat kesimpulan sebagai berikut :

1. Besar nilai stabilitas, nilai flow dan nilai Indirect Tensile Strength pada sampel lab lebih besar daripada sampel hasil coring di lapangan, hal ini dikarenakan oleh beberapa faktor, seperti terkontrolnya suhu campuran saat pembuatan sampel di lab sehingga nilai stabilitas yang dicapai lebih besar dan nilai flow yang didapat lebih tercukupi. Selain itu variasi pemadatan yang dilakukan merupakan faktor yang sangat berpengaruh. Saat di lab dilakukan 75 kali pemadatan untuk setiap sampel, sedangkan saat dilapangan hanya dilakukan 10, 15 dan 20 variasi pemadatan.

2. Besarnya nilai Skid Resistance dari beberapa variasi gilasan sebanyak 10 lintasan, 15 lintasan dan 20 lintasan berturut-turut menurun. Semakin banyaknya gilasan yang dilakukan maka akan semakin rendah pula nilai Skid Resistance yang didapatkan. Hal ini menunjukkan bahwa semakin kecil nilai koefisien PrI semakin baik tingkat kerataan aspal. Sebaliknya, semakin besar nilai koefisien PrI mengindikasikan tekstur permukaan jalan yang kasar dan meningkatkan kekesatan permukaan jalan (skid resistance). 


\section{UCAPAN TERIMAKASIH}

Ucapan terima kasih kepada Ir. Ary Setyawan, M.Sc., Ph.D. dan Ir. Agus Sumarsono, MT yang telah membimbing, memberi arahan dan masukan dalam penelitian ini.

\section{REFERENSI}

RSNI 03-1737-1989, Pelaksanaan Lapis Campuran Beraspal Panas.

Setyawan A., Sarwono D. 2006. Handout Mata Kuliah Teknologi Bahan Perkerasan Jalan. Universitas Sebelas Maret. Surakarta.

Akhmad, A. 2014. Kajian Lapangan Slurry Seal Untuk Pemeliharaan Perkerasan Jalan (Tinjauan Uji Kedalaman Tekstur dan Analisa Biaya. Skripsi, Universitas Sebelas Maret.

Iskandar, I. 2016. Sifat-Sifat Marshall dan Resilient Modulus pada Thin Surfacing Hot Mix Asphalt dengan Polymer Modified Bitumen. Skripsi, Universitas Sebelas Maret.

Kurniawan, R. 2016. Pengaruh Bitumen Modifikasi Ethylene Vinyl Acetete (EVA) Pada Asphalt Concrete (AC) Dan Thin Surfacing Hot Mix Asphalt (TSHMA) Terbadap Uji Kekesatan, UCS, ITS, Permeabilitas Dan ITSM. Skripsi, Universitas Sebelas Maret.

Purnomo, H 2014. Karakteristike Ultra Thin Surfacing Hot Mix Asphalt Ditinjau Dari Nilai Marshall, Kuat Tarik Tidak Langsung, Kuat Tekan Bebas, Dan Permeabilitas. Skripsi, Universitas Sebelas Maret.

http://pavementinteractive.org 